www.conferenceie.ase.ro

\title{
GIS AND BANKING
}

Florin-Cristian MIHAI

Bucharest University of Economic Studies, Romania

fcmihai@gmail.com

\begin{abstract}
The banking sector has been a topic of continuous change and improvement both at political and administrative levels in Romania. Starting to use location analytics, will provide a new way of viewing the development of a banking system. The current paper proposes a GIS workflow regarding the use of geospatial data in the banking sector based on workflows that occurred daily and different type of data to be integrated. The analysis aggregates different financial kpi on Bucharest neighborhoods levers to see where there are high and low performances. The required data and the process for the the proposed analysis are briefly described. The current results rely on data for Bucharest, but the analysis is created in a way that can be used on a bigger scale. Limitations and future research are detailed. The analysis is build using the integration between Microsoft SQL Server Express as a enterprise database and a GIS software suite, where the results are viewed through a dedicated dashboard.
\end{abstract}

Keywords: banking, dashboard, financial kpi, geospatial data, software integration.

JEL classification: G2

DOI: $10.12948 / \mathrm{ie} 2019.04 .23$

\section{Introduction}

In the modern world, everything in our day to day activities is involved around a financial institute, most of the time it is a bank. The need of the customer and of the market requires that the banking system develop and implement different tools, in order to gain insight of the market, to fulfill the need of the new customer and to position in a more competitive role.

Due to these challenges, the banking industry undergoes drastic changes of improving communication and their technology. In an era of on growing technologies, we can use new and integrated new tools that can help in shaping new perspective regarding economics and Geographic Information System (GIS) technologies [1]. GIS technologies are used in more and more domains [2], [3], where the managers need a location based perspective of their assets and other strategic information so that they can make the best decision regarding the business [4], [5].

Nowadays, we can use GIS in the banking sector for the following purposes: expansion of customer base and managing its database, improving quality of the services, increasing consumer satisfaction, consistent business/ financial growth and expansion, increase in profitability. For any of the purposes mention, you can implement different workflows and analysis based on the area of interest in which you want to use GIS technologies integrated with different financial data [6], [7].

The GIS analysis for the banking sector, described in this study, it is resumed on Bucharest area and the data has been collected from various source and created based on a script to randomize values. This analysis is defined based on a model which can be used on a bigger scale. The purpose it is to identify sub-administrative units (neighborhoods or districts) with satisfactory financial key performance indicators (kpi) and the one with the lowest. Also for each sub-administrative unit there have been collected variable data (demographic, economic) which can help understand the performance of a banking agency, and the same data is collected 
and associated for the area of interest of each location.

Regarding the financial kpi, it has been taken in consideration only input revenue values and output revenue values. Input and output revenue value can be defined for any kind of financial transaction that takes place in a banking agency. The result is used in an web based dashboard with sub-administrative unit data viewed based on the kpi values resulted from the analysis define.

\section{Creating the required data}

Implementing a new tool or a new analyze in the banking sector implies a complex workflow, in which specific data are needed. The process of gathering the specific data has encounter some complex objectives and condition. For this paper a Sql Server Express database was used, which allows integration with a GIS software, in this case it was used from ArcGIS software suits develop by ESRI. ArcGIS software has diverse set of tools for mapping and spatial analysis and creates insight for the questions you need answers. This software has been chosen, because it offers the needed workflows to integrate different solution, in this case with a SQL database, such as: all required data stored in a single place, spatial and non-spatial data, from different data formats, has ready to use spatial analysis tools, the possibility to use different scripting language as geoprocessing tools, and so many more.

\subsection{Computing banking agency data}

It has been collected in a csv. file that stores the location of 85 bank agency using latitude and longitude coordinates, that are spreaded around Bucharest. For this step, the location has been taken using the website of one of the major banks in Romania. This data then, was appended in the SQL database. The major problem in creating our data to be used in the proposed analysis it is the access to real financial data from the banking agency. In this situation, the following attributes have been created based on a script (Figure 1.). The script was written in Python and uses a dedicated library for values randomization. With this script random values have been created for each agency, for each of the following attributes:

- input data - financial value for the amount that it goes in an agency, with values between 20.000 and 1.000.000;

- output data - financial value for the amount that it goes out from an agency, with values between 8.000 and 600.000 ;

- number of employees - values between 5 and 50;

The values for input and output are defined in the national currency of Romania, RON (Romanian leu).

\section{import numpy \\ def getRandomValue(): \\ return numpy.random.randint(minim value, maxim value)}

Figure 1. Python script to create random data

\subsection{Computing neighborhood data}

The current area of Bucharest, situated inside the Ring Road, has 77 polygons representing the sub-administrative unit (neighborhoods). Not all of them are under the administration of the city hall of Bucharest. The shape and surface of each polygon was manually created using the ArcGIS Pro software component [9], and are based on an old topographic map from between 
www.conferenceie.ase.ro

the 1970 and 1980 and thus having some difference compared to present day. The data was created in the SQL database due to the software integration.

For each neighborhood it has been defined the following attributes: name, total population, total household, unemployment population, total purchasing power. This data was collected using a service provide by the ArcGIS software, to enrich a dataset with available data. The data it is provided from Michael Bauer Research GmbH company [10] based on National Institute of Statistics and Eurostat. Data for total population, total household and total purchasing power are from the year 2017 and the unemployment population from 2016.

\section{Creating the workflow and the analysis}

After integrating all the required data in the SQL database, spatial and non-spatial data, from different data formats, a workflow model, as shown in Figure 2, was created for two direction regarding the analyze, which will have two results. The workflow model was made so that the process of using it can be iterative for both of the results, where any of the parameter can or added new instruments and criteria's, data, parameters so that we can make conclusive results. Creating two results was proposed so that there will be 2 perspective of assessing the use of this types of analysis in the banking sector.

The main steps in creating the workflow model are:

- the required data with all the needed information it is stored in SQL database;

- ensuring that all the data have a spatial reference that can be use to help identify the correct position on the map;

* first result - overview image

- position points representing banking agency on the map;

- walk time analysis from the above mention points;

- adding neighborhoods with population data;

* second result - aggregate data

- creating an unique ID for the agency based on the neighborhood in which resides;

- creating SQL query to aggregate agency data for input/output based on ID and assigned to neighborhoods;

- adding neighborhoods with population data;

- adding and creating dedicated dashboard for visualization query results with any new modification on the input/output data;

- this workflow provides a way so that it can have the possibility to change the parameters or add new steps and tools; 


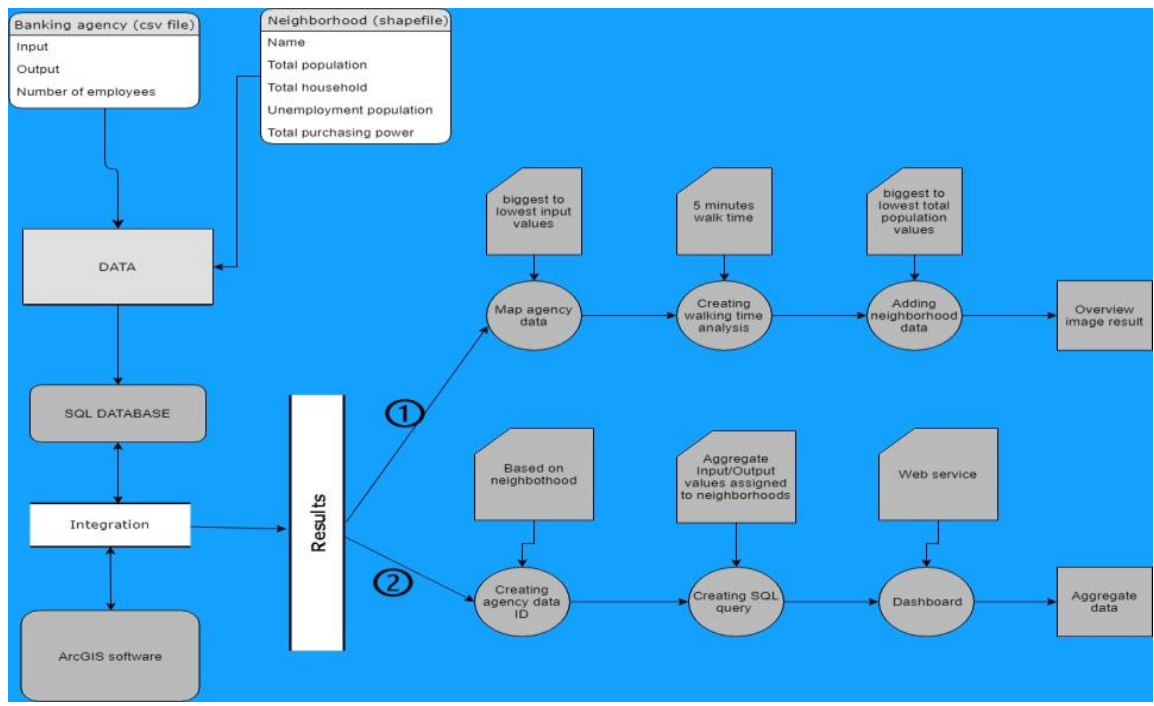

Figure 2. Workflow model

\subsection{Results of the analysis}

Each banking agency has been position using the geographical coordinates collected. And for each agency a walk time analysis has been created, representing a polygon around each point in the map, from which a person can walk for a maximum of about 5 minutes. The average walking speed of a person was defined as being 5 kilometers per hour. The spatial representation of the first analysis result are shown in Figure 3., and can be described as such: overview image for the distribution of the agencies location, the locations where we have the highest and the lowest input and output values, and a 4-class quantile statistic method representation of the population data for the neighborhoods.

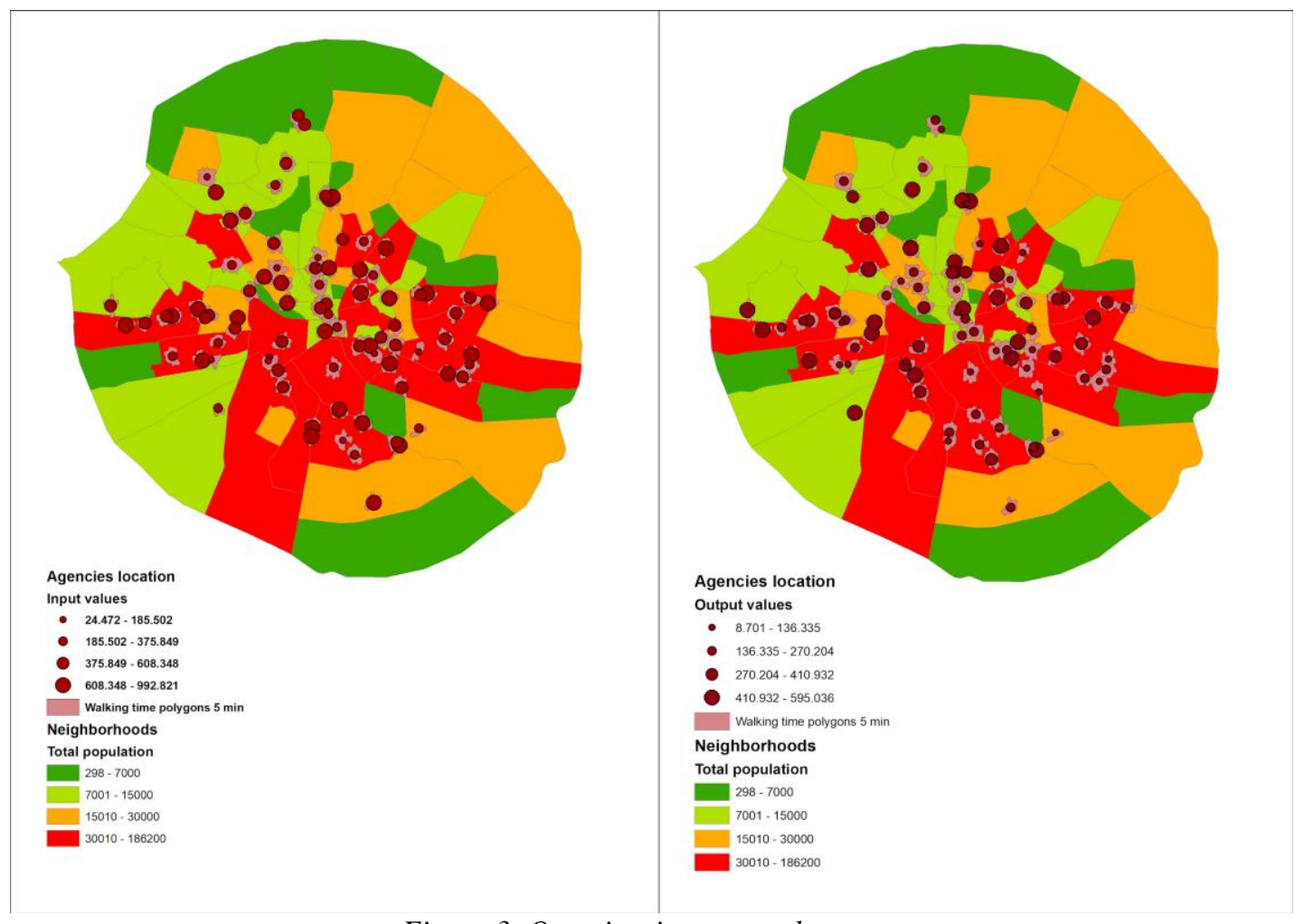

Figure 3. Overview image result 
Figure 4 shows the result of the second analysis, meaning a query created directly in the SQL database and then imported in ArcGIS software base on the integration between the two software solutions. There are only 44 neighborhoods from the total of 77 , where there is minimum one agency with the same ID. The neighborhoods are displayed using a 3-class quantile statistic method, where with deeper color are high values for input and output data from the agencies, and brighter color lowest values. With the query created and integrated, with any change to the data in SQL, it will be showed in the map. This result was then published as a web service a used to create a web dashboard within a cloud based service, to be viewed and shared to a range of person that don't need GIS background to understand.

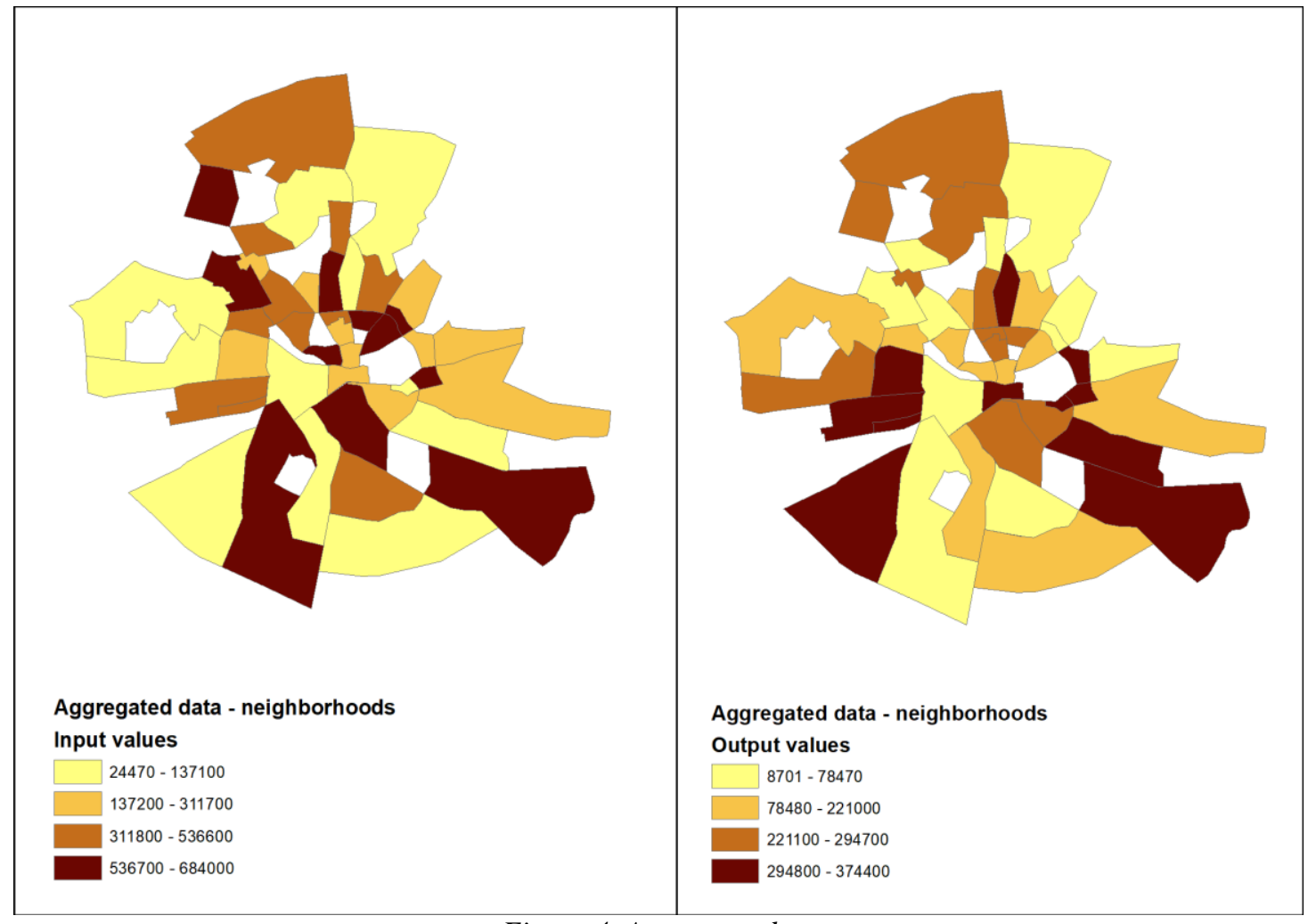

Figure 4. Aggregate data

\section{Limitations and future research}

In the process of creating the GIS analysis presented in this paper, some limitation have been identified and asses this limitation, which is the subject of further research, can improve the analysis and create new results and insights on how this type of tools can be used in the banking sector, such as:

- taking into consideration that the data used for each agency to be based on real inputs.

- having a wide variety of application from different departments based on a more complex set of data particular to the banking sector.

- collecting and taking into consideration additional data, which has a location base component, resulting in creating a new instrument based on location.

- taking into consideration the population behavior in choosing the bank that can satisfied their needs, by creating a specific form with location based questions.

- integrating in the GIS perspective existing tools already developed and used in the banking sector, in order to grab a wide perspective of the advantages gained by the use of them. 
www.conferenceie.ase.ro

- automating the process of updating the data from the banking agency regarding the input and output to the neighborhoods daily or at the certain period of time, define in the process.

\section{Conclusions}

The banking industry has been undergoing drastic changes, reflecting a number of underlying developments. GIS based solutions can be developed in an integrated environment to help banks in decision making, Strategic planning, Effective resource management and Operations management to achieve their business objectives.

The research results obtained so far are leading towards the idea that the use of modern location technology entails numerous advantages enabling effective decision substantiation by considering and accounting for a huge range of performance criteria. In this context the research lead to the following conclusions:

C1. Two different software solutions ca easily be integrated to help in assesing existing data and gain insight.

C2. Either of the two analysis results can help identify areas or neighborhoods with potential where is no coverage from a banking agency.

C3. Thru the walking time area, we can see that lots of points of interest are creating competition among themselves, because one person can reach in 5 minutes of walking from one agency to another.

\section{References}

[1] K. Pogodzinski, Economic development and GIS. 2012 USA: ESRI Press.

[2] R. Tomlinson, Thinking about GIS, Vol. 5, 2013, Esri Press

[3] G.I. Thrall, Business Geography and new real estate market analysis, 2002, Oxford

[4] M. Zenus, How geospatial analytics can give your business a competitive edge, March 2, 2017

[5] M. Dârdală and A. Reveiu, Using Raster Based Solutions to Identify Spatial Economic Agglomerations, Informatica Economică, vol. 17, nr. 1, pp. 131-143, 2013, Editura INFOREC, Bucureşti

[6] J. Mohammad, U. Srinivas, R. Nagesh, V.R. Srinatha, An integrated approach for Banking GIS, Geospatial World, 2009

[7] E.H. MacDonald, GIS in Banking: Evaluation of Canadian Bank Mergers, Canadian Journal of Regional Science, vol. XXIV, pp. 419-442, 2001

[8] A. Reveiu and M. Dârdală, 2011, Techniques for Statistical Data Visualization in GIS, Informatica Economică, 2011, vol. 15, no. 3, pp. 72-79

[9] M. Law and A. Collins, Getting to Know ArcGIS Pro, Vol. 1, 2016, Esri Press

[10] M. Bauer, Research GmbH, http://www.english.mb-research.de/, 2019 